\title{
Expression of Tight Junction Proteins According to Functional Dyspepsia Subtype and Sex
}

\author{
Ju Yup Lee, ${ }^{1,2}$ Nayoung Kim, ${ }^{1,3 *}$ Yoon Jin Choi, ${ }^{1}$ Ji Hyun Park, ${ }^{3}$ Hassan Ashktorab, ${ }^{4}$ Duane T Smoot, ${ }^{5}$ and Dong Ho Lee ${ }^{1,3}$ \\ ${ }^{\prime}$ Department of Internal Medicine, Seoul National University Bundang Hospital, Seoungnam, Gyeonggi-do, Korea; ${ }^{2}$ Department of Internal \\ Medicine, Keimyung University School of Medicine, Daegu, Korea; ${ }^{3}$ Department of Internal Medicine and Liver Research Institute, Seoul \\ National University College of Medicine, Seoul, Korea; ${ }^{4}$ Department of Medicine and Cancer Center, Howard University College of Medicine, \\ Washington, District of Columbia, USA; and ${ }^{5}$ Department of Medicine, Meharry Medical Center, Nashville, Tennessee, USA
}

\section{Background/Aims}

To determine whether the expression of tight junction proteins (TJPs) differs depending on the subtype of functional dyspepsia (FD) and sex.

\section{Methods}

Control $(n=95)$ and FD $(n=165)$ groups based on Rome III criteria were prospectively enrolled. Gastric mucosal mRNA expression levels of various TJPs (claudins [CLDN] 1, 2, and 4; zonula occludens-1; occludin [OCLN]) were assessed by reverse transcription polymerase chain reaction. Western blot was performed to determine the levels of various TJPs. Helicobacter pylori infection status was evaluated by histology, rapid urease test, and culture. Questionnaires were analyzed.

\section{Results}

In all groups irrespective of $H$. pylori, FD group showed significantly higher CLDN2 mRNA levels than control group $(P=0.048)$. The level of CLDN4 mRNA expression was significantly lower in female FD group than in male FD group $(P=0.018)$. In $H$. pylori uninfected subjects, the level of CLDN1 mRNA expression in female FD group was significantly lower than that of male FD group ( $P$ $=0.014)$. The level of CLDN2 mRNA expression was significantly higher in the male postprandial distress syndrome $(P=0.001)$ and male epigastric pain syndrome $(P=0.023)$ groups than in the male control group. In Western blot analysis, the expression of OCLN was significantly elevated 48 hour after the culture with H. pylori strain 43504.

\section{Conclusions}

H. pylori can affect a variety of TJPs, particularly claudin-4 and occludin. Claudin-2 is thought to be involved in FD irrespective of $H$. pylori status, especially in the pathophysiology of male FD.

(J Neurogastroenterol Motil 2020;26:248-258)

\section{Key Words}

Claudin-2; Dyspepsia; Helicobacter pylori; Occludin; Tight junction proteins

\section{Received: October 27, 2019 Revised: March 13, 2020 Accepted: March 13, 2020}

$\Theta$ This is an Open Access article distributed under the terms of the Creative Commons Attribution Non-Commercial License (http:// creativecommons. org/licenses/by-nc/4.0) which permits unrestricted non-commercial use, distribution, and reproduction in any medium, provided the original work is properly cited.

*Correspondence: Nayoung Kim, MD, PhD Department of Internal Medicine, Seoul National University Bundang Hospital, 82, Gumi-ro 173beon-gil, Bundang-gu, Seongnam, Gyeonggi-do 13620, Korea Tel: +82-31-787-7008, Fax: +82-31-787-4051, E-mail: nakim49@snu.ac.kr 


\section{Introduction}

Functional dyspepsia (FD) is usually a functional disorder that is characterized as chronic upper abdominal discomfort without apparent evidence of organic disease. ${ }^{1,2} \mathrm{FD}$ is classified into 2 subtypes according to the patient's symptoms: postprandial distress syndrome (PDS), which is mainly caused by meal-induced dyspepsia, and epigastric pain syndrome (EPS), which is mainly expressed as epigastric pain or epigastric burning. ${ }^{2}$

Most functional gastrointestinal disorders (FGIDs) are known to have a higher prevalence in women., ${ }^{3,4}$ Although gender difference is not obvious depending on the study area or method, ${ }^{5-7}$ many studies have reported a higher prevalence among women, ${ }^{8}$ and being female is an important risk factor for FD. ${ }^{9}$ However, to date, the underlying pathogenesis for the gender difference in FD, especially that depending on the FD subtype, has not been investigated in detail. For example, epigastric burning and pain was reported to be more frequent in female FD, which was closely related with anxiety score; however, the expression of ghrelin was lower in the male FD PDS type, and the expression of nociception-related genes was higher in the male FD EPS type, whereas there was no difference among female patients with FD. ${ }^{10}$

The pathophysiology of FD is very complex and not fully understood. Gastroduodenal motor and sensory dysfunction, impaired mucosal integrity, Helicobacter pylori infection, low-grade immune activation, and dysregulation of the gut-brain axis are considered to be the main pathophysiological characteristics. ${ }^{2,11}$ Among these, low-grade inflammation in the lamina propria damages the mucosal barrier of the gastrointestinal (GI) tract, increasing the pathophysiological symptoms and leading to increased intestinal permeability. ${ }^{12}$ Tight junctions are the important structures for barrier function in epithelial cells. ${ }^{13}$ Tight junction molecules are surface-expressing core proteins that include claudins (CLDNs), occludin (OCLN), and junctional adhesion molecules, and these molecules bind directly to the scaffold proteins zonula occludens (ZOs). ${ }^{13}$ Tight junctions play an important role in cell adhesion and permeability and thus contribute to maintenance of epithelial physiology. ${ }^{13,14}$ However, to date, their role in the stomach has not been evaluated in the context of the pathophysiology of FD. They are likely related to the complex stomach structure involved in acid secretion and $H$. pylori infection-related gastritis. A Japanese group showed that CLDN3 mRNA expression in the duodenal mucosa was increased in FD patients. ${ }^{15}$ Our team also reported that the decrease in ZO-1 was an important factor in patients with irritable bowel syndrome-diarrhea dominant type but only in females. ${ }^{16}$ Based on this background, we hypothesized that tight junction proteins (TJPs) in the stomach could play a role in FD that could differ depending on sex and FD subtype. Thus, we aim to determine whether the expression of various TJPs related to intestinal permeability changes differed in patients with FD and whether the differences depended on sex and FD subtype.

\section{Materials and Methods}

\section{Subjects}

From March 2013 to May 2016, we prospectively enrolled study subjects. Korean subjects who received upper GI endoscopy were enrolled. Questionnaires about FD, emotional state, and quality of life $(\mathrm{QoL})$ were obtained from subjects under the guidance of a welltrained interviewer. Subjects who had a GI surgery history, a recent peptic ulcer history, or any malignancy history were excluded. Nonsteroid anti-inflammatory drug or anticoagulant users and patients who take medications due to chronic disorders were also excluded.

According to the Rome III criteria, ${ }^{17,18}$ the control or FD group were assigned. FD group were classified into the PDS, EPS, and mixed subtype based on the Rome III criteria. ${ }^{19}$ The control group was defined as individuals who had no GI symptoms and showed normal endoscopic findings. This study was approved by the Institutional Review Board (B-1101/119-010).

\section{Severity of Dyspepsia Symptoms, Assessment of Anxiety, Depression, and Quality of Life}

The scores of epigastric pain/burning, postprandial fullness, early satiation, and overall abdominal pain (not restricted to the epigastric area) were ranked by a 5 -point scale $(0$, none; 1 , mild; 2, moderate; 3, severe; 4, very severe) using a validated Korean version of Talley's bowel disease questionnaire. ${ }^{20}$ The Bristol Stool Form Scale ${ }^{21}$ was used to evaluate stool consistency, and the number of bowel movements was also estimated. The anxiety and depression of the study subjects was evaluated using the hospital anxiety and depression scale (HADS). ${ }^{22}$ It is subclassified into anxiety and depression scales, both of them contains 7 items. Each response is ranked on a 4-point (0-3) scale. As higher scores by HADS demonstrating more depressive or anxious subjects, with a score more than 7 for each scale revealing potential anxiety or depression. ${ }^{23}$ To evaluate the QoL, the World Health Organization quality of life scale field trial version (WHOQOL-BREF) was used. ${ }^{24}$ WHOQOL-BREF contains questionnaires about overall QoL 
and general health with 4 domains, including physical and psychological, social, and environmental domain (overall: range 0-100, domain: range 0-20, higher scores mean a higher QoL). All these 3 questionnaires have been validated in Korea. ${ }^{20,25,26}$

\section{Upper Endoscopy, Histology, and Helicobacter pylori Evaluation}

Gastric biopsy specimens were obtained from the antrum and body for histology during the upper endoscopy. These biopsy specimens were used to measure the mRNA expression of CLDN1, CLDN2, CLDN4, OCLN, and ZO-1. The H. pylori infection status was evaluated by histology by using the updated Sydney system, ${ }^{27}$ CLOtest (Delta West, Bentley, Australia), and culture. If one of these 3 invasive $H$. pylori tests was positive, the patient was diagnosed with current $H$. pylori infection. When these tests were all negative then serum anti-H. pylori IgG antibody test (Genedia ELISA; Green Cross Medical Science Corp, Eumsung, Korea) was performed. If the $H$. pylori serology was positive, but no bacteria were found in the invasive studies, it was defined as a past $H$. pylori infection. Similarly, if the patient has $H$. pylori eradication history then this case was also regarded as past $H$. pylori infection. The absence of both current and past $H$. pylori infections was defined as the $H$. pylori uninfected group.

\section{Quantitative Reverse Transcription Polymerase Chain Reaction}

To stabilize and protect RNA from degradation, gastric biopsy specimens were stored in RNAlater Solution (Ambion, Austin, TX, USA) at $4^{\circ} \mathrm{C}$. According to manufacturer's recommendations, total RNAs were extracted from the gastric mucosal biopsy specimen using TRIzol reagent (Invitrogen, Carlsbad, CA, USA), and RNA purification was done by using RNeasy mini kits (Qiagen, Valencia, CA, USA). Synthesis of cDNA was performed using $1 \mu \mathrm{g}$ of total RNA with a High Capacity cDNA kit (Applied Biosystems, Foster City, CA, USA). The thermal cycling parameters for the reverse transcription were as follows: 10 minutes at $25^{\circ} \mathrm{C}, 120$ minutes at $37^{\circ} \mathrm{C}$, and 5 minutes at $85^{\circ} \mathrm{C}$. Quantitative reverse transcription polymerase chain reaction (qRT-PCR) was performed in triplicate using a StepOnePlus Real-time PCR system (Applied Biosystems) with SYBR Premix Ex TaqTM (Takara Bio, Shiga, Japan). Detail information about the primers of each TJPs were described in Supplementary Table. The thermal cycling conditions were as follows: initial denaturation at $95^{\circ} \mathrm{C}$ for 10 seconds, followed by 40 cycles of $95^{\circ} \mathrm{C}$ for 5 seconds and $60-65^{\circ} \mathrm{C}$ for 33 seconds. Relative expression levels of mRNA from the target genes were compared with that of the endogenous control $\beta$-actin using the $2^{-\Delta \mathrm{Ct}}$ method.

\section{Helicobacter pylori Infection of HFE-145 Cells}

HFE-145 normal male human gastric epithelial cells were kindly provided by Dr Hassan Ashktorab and Duane T Smoot (Howard University, Washington, DC, USA). Cells were seeded onto 6-well slide chambers or 6-cm diameter petri dishes (Thermo Fisher Scientific Nunc, Inc, Waltham, MA, USA). Cells were grown in medium with $2.5 \%$ fetal bovine serum and without antibiotics for 20 hours at $37^{\circ} \mathrm{C}$ prior to $H$. pylori infection. Cells were washed once with sterile phosphate buffered saline (PBS), and then $H$. pylori ATCC 43504 (O4 strain; cag $A+$ and vacA+) that was purchased from American Type Culture Collection (ATCC, Manassas, VA, USA) were added at a multiplicity of infection of 100:1 for different time points, followed by washing with PBS 6 times to remove nonadherent bacteria. Bacteria were cultured under microaerophillic conditions $\left(5 \% \mathrm{O}_{2}, 10 \% \mathrm{CO}_{2}\right.$, and $\left.85 \% \mathrm{~N}_{2}\right)$ at $37^{\circ} \mathrm{C}$. The effect of $H$. pylori infection on expression of ZO-1, OCLN, and CLDN2 in human gastric cell lines was investigated.

\section{Western Blot Analysis}

After 24 hours and 48 hours of co-culture, cells were lysed with RIPA buffer (Cell Signaling Technology, Beverly, MA, USA) after washing twice with $\mathrm{PBS}$, and BCA protein assay was performed for determining protein concentration (Pierce, Rockford, IL, USA). Cell extracts (20 $\mu \mathrm{g}$ protein) were subjected to $10 \%$ SDS-PAGE and the separated proteins were transferred to PVDF membranes. After blocking the non-specific binding sites with non-fat dry milk, the membranes were incubated with anti-Claudin-2 antibodies (1:500; 51-6100; Thermo Fisher Scientific, Inc, Waltham, MA, USA), anti-ZO-1 antibodies (1:1000, 61-7300; Thermo Fisher Scientific, Inc), and anti-Occludin antibodies (1:1000; 33-1500; Thermo Fisher Scientific, Inc) at $4{ }^{\circ} \mathrm{C}$ overnight, then blots were incubated with secondary antibody (goat-anti rabbit antibody, 1:1000; Santa Cruz Biotechnology, Dallas, TX, USA). Detection was achieved with an enhanced chemiluminescence agent (Amersham BioSciences, Buckinghamshire, UK).

\section{Statistical Methods}

Data are presented as the median (interquartile range) or mean $\pm \mathrm{SD}$. Categorical variables are presented as numbers and percentages and were analyzed by the Chi-square test or Fisher's exact test. Continuous variables were analyzed using the Mann-Whitney $U$ test between 2 groups or the Kruskal-Wallis test among 3 and more groups. Post hoc analysis was performed by the Mann-Whitney 
$U$ test. SPSS software (version 20.0; IBM Corp, Armonk, NY, USA) was used for Statistical analyses. Two-sided $P$-values of $<$ 0.05 were considered statistically significant.

\section{Results}

\section{Characteristics of the Subjects}

Among 260 enrolled subjects, 95 and 165 subjects were assigned to the control and FD groups, respectively. Table 1 summarizes the baseline characteristics of the study subjects. There was no difference in age between the control and FD groups. There was no significant different in the male ratios between the control and FD groups $(44.2 \%$ vs $36.4 \%, P=0.236$ ). There were no significant sex differences in the percentage of $H$. pylori infection status and FD subtypes.

Current $H$. pylori infection subjects was $31.6 \%$ in the control group and $44.8 \%$ in the FD group. To exclude the effect of $H$. pylori on TJP, the analysis was performed in the $H$. pylori uninfected excluding current as well as past $H$. pylori infection subjects.

Comparing the FD and control groups, patients with FD had a higher mean HADS score for anxiety than the controls (5.8 \pm 3.3 vs $7.6 \pm 3.5, P=0.004)$. In the WHOQOL-BREF questionnaires, the FD group demonstrated a sex difference on the WHOQOL-BREF. That is, female patients with FD had lower physical domain and social domain scores than male patients with FD (physical, $12.2 \pm 3.2$ vs $14.6 \pm 2.5$; social, $11.5 \pm 3.9$ vs 14.2 $\pm 1.8 ; P=0.035$ and 0.016 , respectively) (Table 1 ).

\section{Tight Junction Protein mRNA Expression Levels Between the Control and Functional Dyspepsia Groups in All Group Irrespective of Helicobacter pylori Status}

FD group showed significantly higher CLDN2 mRNA levels than those of control group $(P=0.048)$, but no differences were observed between male $11.5 \pm 3.9$ vs $14.2 \pm 1.8$ and female FD group. The level of CLDN4 mRNA expression was significantly lower in female FD group than those of male FD group $(P=$

Table 1. Baseline Characteristics of the Study Subjects

\begin{tabular}{|c|c|c|c|c|c|c|c|c|c|}
\hline \multirow[b]{2}{*}{ Characteristics } & \multicolumn{3}{|c|}{ Control $(\mathrm{n}=95)$} & \multicolumn{3}{|c|}{$\mathrm{FD}(\mathrm{n}=165)$} & \multicolumn{3}{|c|}{$P$-value } \\
\hline & $\begin{array}{c}\text { Total } \\
(\mathrm{n}=95)\end{array}$ & $\begin{array}{c}\text { Male } \\
(\mathrm{n}=42)\end{array}$ & $\begin{array}{l}\text { Female } \\
(\mathrm{n}=53)\end{array}$ & $\begin{array}{c}\text { Total } \\
(\mathrm{n}=165)\end{array}$ & $\begin{array}{c}\text { Male } \\
(\mathrm{n}=60)\end{array}$ & $\begin{array}{c}\text { Female } \\
(\mathrm{n}=105)\end{array}$ & $\begin{array}{c}\text { Control vs } \\
\text { FD }\end{array}$ & $\begin{array}{c}\text { Control } \\
\text { (male vs female) }\end{array}$ & $\begin{array}{c}\text { FD } \\
\text { (male vs female) }\end{array}$ \\
\hline Age (yr) & $55.0 \pm 11.3$ & $53.5 \pm 12.8$ & $56.2 \pm 9.9$ & $51.4 \pm 15.4$ & $49.7 \pm 13.2$ & $52.4 \pm 16.4$ & 0.053 & 0.250 & 0.275 \\
\hline Male & $42(44.2)$ & $42(100)$ & 0 & $60(36.4)$ & $60(100)$ & 0 & 0.236 & & \\
\hline H. pylori status & & & & & & & 0.735 & 0.723 & 0.785 \\
\hline Current infection & $42(31.6)$ & $17(40.5)$ & $25(47.2)$ & $74(44.8)$ & $25(41.7))$ & $49(46.7)$ & & & \\
\hline Past infection & $23(44.2)$ & $10(23.8)$ & $13(24.5)$ & $33(20.0)$ & $12(20.0)$ & $21(20.0)$ & & & \\
\hline Uninfected & $30(24.2)$ & $15(35.7)$ & $15(28.3)$ & $58(35.2)$ & $23(38.3)$ & $35(33.3)$ & & & \\
\hline Subtype in FD & & & & & & & & & 0.405 \\
\hline PDS & & & & $44(26.7)$ & $19(31.7)$ & $25(23.8)$ & & & \\
\hline EPS & & & & $42(25.5)$ & $10(16.7)$ & $32(30.5)$ & & & \\
\hline Mixed & & & & $79(47.9)$ & $31(51.7)$ & $48(45.7)$ & & & \\
\hline \multicolumn{10}{|l|}{ HADS score ${ }^{a}$} \\
\hline Anxiety & $5.8 \pm 3.3$ & $5.9 \pm 3.2$ & $5.1 \pm 3.5$ & $7.6 \pm 3.5$ & $7.3 \pm 2.4$ & $7.9 \pm 4.1$ & 0.004 & 0.375 & 0.882 \\
\hline Depression & $6.5 \pm 3.5$ & $6.4 \pm 3.7$ & $7.1 \pm 3.7$ & $6.7 \pm 3.5$ & $6.0 \pm 2.8$ & $7.2 \pm 3.7$ & 0.679 & 0.357 & 0.353 \\
\hline \multicolumn{10}{|c|}{ WHOQOL-BREF score ${ }^{a}$} \\
\hline $\begin{array}{l}\text { Overall quality of life } \\
\text { and general health }\end{array}$ & $6.5 \pm 3.3$ & $6.4 \pm 3.4$ & $6.6 \pm 3.6$ & $6.1 \pm 3.3$ & $6.8 \pm 3.3$ & $5.5 \pm 3.5$ & 0.586 & 0.856 & 0.092 \\
\hline Physical domain & $13.0 \pm 3.8$ & $12.7 \pm 4.7$ & $13.5 \pm 1.6$ & $13.3 \pm 3.1$ & $14.6 \pm 2.5$ & $12.2 \pm 3.2$ & 0.918 & 0.799 & 0.035 \\
\hline Psychological domain & $12.2 \pm 3.8$ & $12.0 \pm 4.2$ & $12.6 \pm 1.8$ & $12.6 \pm 3.6$ & $13.5 \pm 2.8$ & $11.8 \pm 2.8$ & 0.925 & 0.799 & 0.168 \\
\hline Social domain & $12.9 \pm 3.9$ & $12.6 \pm 4.6$ & $13.5 \pm 2.2$ & $12.7 \pm 3.4$ & $14.2 \pm 1.8$ & $11.5 \pm 3.9$ & 0.634 & 1.000 & 0.016 \\
\hline Environment domain & $12.4 \pm 3.9$ & $12.5 \pm 3.3$ & $12.1 \pm 2.4$ & $12.1 \pm 3.7$ & $12.5 \pm 1.8$ & $11.7 \pm 3.1$ & 0.660 & 0.360 & 0.905 \\
\hline
\end{tabular}

${ }^{a} \mathrm{n}=21$ (male 14 and female 7) in control group and $\mathrm{n}=31$ (male 14 and female 17) in FD group.

FD, functional dyspepsia; H. pylori, Helicobacter pylori; PDS, postprandial distress syndrome; EPS, epigastric pain syndrome; HADS, hospital anxiety and depression scale; WHOQOL-BREF, world health organization quality of life abbreviated version.

Data are presented as mean $\pm \mathrm{SD}$ or number $(\%)$. 
Table 2. Comparison of Tight Junction Protein mRNA Expression Levels Between Control and Functional Dyspepsia Groups in All Subjects Irrespective of Helicobacter pylori

\begin{tabular}{|c|c|c|c|c|c|c|c|c|c|}
\hline \multirow{2}{*}{$\begin{array}{c}\text { Tight junction } \\
\text { protein }\end{array}$} & \multicolumn{3}{|c|}{ Control $(\mathrm{n}=95)$} & \multicolumn{3}{|c|}{$\mathrm{FD}(\mathrm{n}=165)$} & \multicolumn{3}{|c|}{$P$-value } \\
\hline & $\begin{array}{c}\text { Total } \\
(\mathrm{n}=95)\end{array}$ & $\begin{array}{c}\text { Male } \\
(\mathrm{n}=42)\end{array}$ & $\begin{array}{l}\text { Female } \\
(\mathrm{n}=53)\end{array}$ & $\begin{array}{c}\text { Total } \\
(\mathrm{n}=165)\end{array}$ & $\begin{array}{c}\text { Male } \\
(\mathrm{n}=60)\end{array}$ & $\begin{array}{c}\text { Female } \\
(\mathrm{n}=105)\end{array}$ & $\begin{array}{c}\text { Control vs } \\
\text { FD }\end{array}$ & $\begin{array}{c}\text { Control } \\
\text { (male vs female) }\end{array}$ & $\begin{array}{c}\text { FD } \\
\text { (male vs female) }\end{array}$ \\
\hline CLDN1 & $1.0(0.6-2.3)$ & $1.1(0.6-2.5)$ & $1.0(0.6-2.1)$ & $0.9(0.5-1.9)$ & $1.2(0.5-2.5)$ & $0.8(0.5-1.5)$ & 0.211 & 0.599 & 0.104 \\
\hline CLDN2 & $1.1(0.6-2.1)$ & $0.9(0.5-1.5)$ & $1.3(0.9-2.7)$ & $1.5(0.7-2.7)$ & $1.3(0.7-2.2)^{\mathrm{a}}$ & $1.6(0.8-3.1)$ & 0.048 & 0.001 & 0.130 \\
\hline CLDN4 & $1.2(0.6-1.9)$ & $1.2(0.7-2.1)$ & $1.2(0.6-1.7)$ & $1.4(0.8-1.9)$ & $1.6(1.1-2.2)^{\mathrm{a}}$ & $1.3(0.7-1.8)$ & 0.137 & 0.970 & 0.018 \\
\hline OCLN & $0.9(0.5-2.4)$ & $0.7(0.5-1.6)$ & $1.0(0.5-2.8)$ & $1.1(0.6-2.3)$ & $1.3(0.7-2.3)^{\mathrm{a}}$ & $1.0(0.6-2.2)$ & 0.177 & 0.206 & 0.492 \\
\hline $\mathrm{ZO}-1$ & $1.4(0.3-8.3)$ & $1.8(0.3-10.9)$ & $1.2(0.3-7.3)$ & $1.0(0.2-4.2)$ & $1.0(0.4-4.4)$ & $0.9(0.2-4.0)$ & 0.195 & 0.499 & 0.521 \\
\hline
\end{tabular}

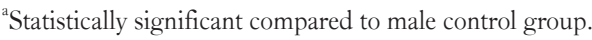

FD, functional dyspepsia; CLDN, claudin; OCLN, occludin; ZO-1, zonula occludens-1.

Data are presented as median (interquartile range).
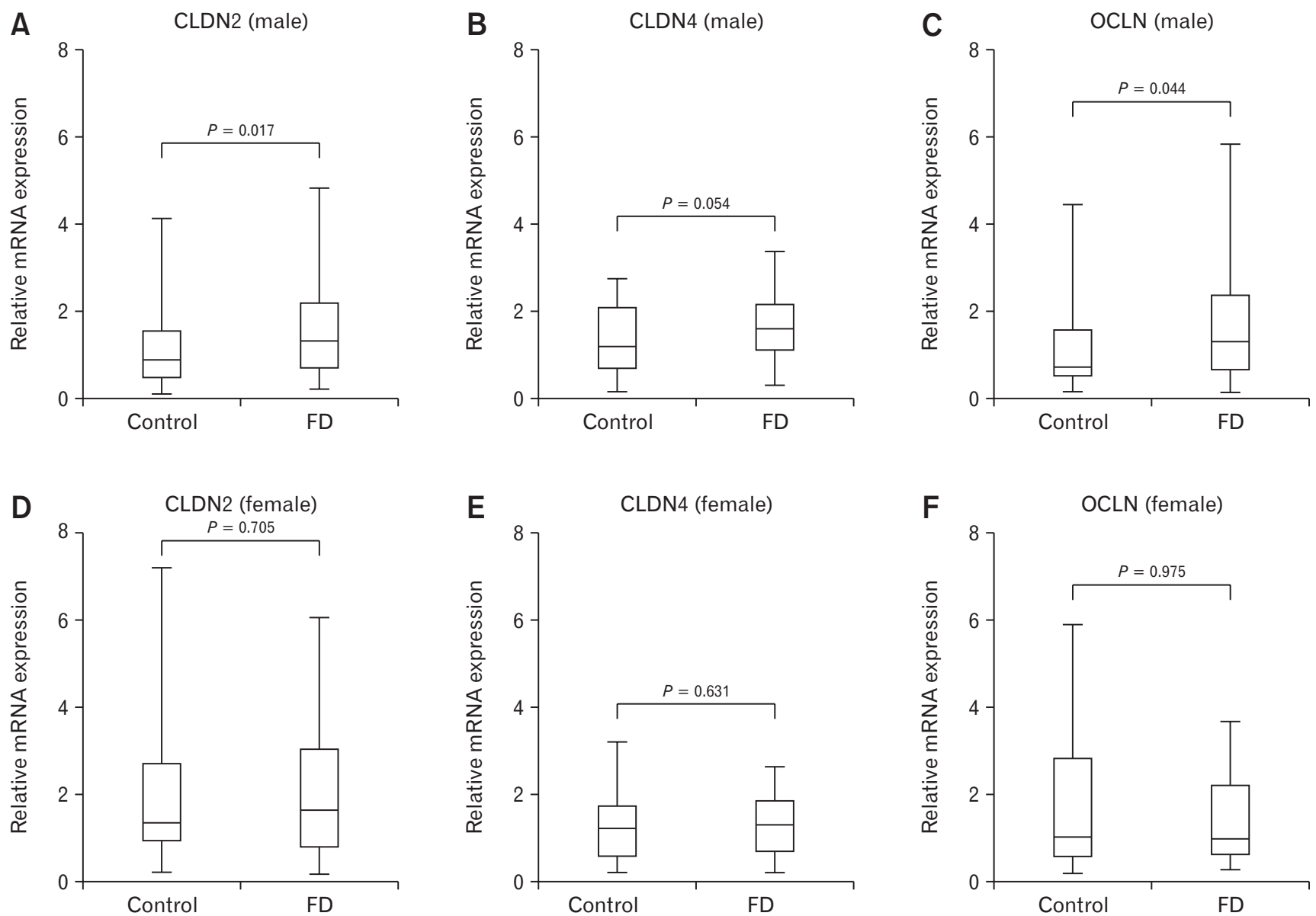

Figure 1. Comparison of tight junction protein mRNA expression levels in the control and functional dyspepsia (FD) groups in all groups irrespective of Helicobacter pylori status. (A-C) Claudin-2 (CLDN2), CLDN4, and occludin (OCLN) mRNA expression were higher in male FD group than those of control group $(P=0.017,0.054$, and 0.044 , respectively). (D-F) There were no significant differences in CLDN2, CLDN4, and OCLN mRNA expression level between female FD group and female control group. Data are expressed as median (interquartile range). 
Table 3. Comparison of Tight Junction Protein mRNA Expression Levels Between Control and Functional Dyspepsia Groups in Helicobacter pylori Uninfected Subjects

\begin{tabular}{|c|c|c|c|c|c|c|c|c|c|}
\hline \multirow{2}{*}{$\begin{array}{c}\text { Tight junction } \\
\text { protein }\end{array}$} & \multicolumn{3}{|c|}{ Control $(\mathrm{n}=30)$} & \multicolumn{3}{|c|}{$\mathrm{FD}(\mathrm{n}=58)$} & \multicolumn{3}{|c|}{$P$-value } \\
\hline & $\begin{array}{c}\text { Total } \\
(\mathrm{n}=30)\end{array}$ & $\begin{array}{c}\text { Male } \\
(\mathrm{n}=15)\end{array}$ & $\begin{array}{l}\text { Female } \\
(\mathrm{n}=15)\end{array}$ & $\begin{array}{c}\text { Total } \\
(\mathrm{n}=58)\end{array}$ & $\begin{array}{c}\text { Male } \\
(\mathrm{n}=23)\end{array}$ & $\begin{array}{l}\text { Female } \\
(\mathrm{n}=35)\end{array}$ & $\begin{array}{c}\text { Control vs } \\
\text { FD }\end{array}$ & $\begin{array}{c}\text { Control } \\
\text { (male vs female) }\end{array}$ & $\begin{array}{c}\text { FD } \\
\text { (male vs female) }\end{array}$ \\
\hline CLDN1 & $0.8(0.5-1.5)$ & $0.8(0.4-3.4)$ & $0.8(0.5-1.3)$ & $1.0(0.7-1.6)$ & $1.5(0.7-2.8)$ & $0.9(0.6-1.2)$ & 0.369 & 0.513 & 0.014 \\
\hline CLDN2 & $0.9(0.5-1.1)$ & $0.6(0.2-1.0)$ & $1.1(0.6-1.5)$ & $1.5(0.7-2.3)$ & $1.3(0.8-1.9)^{\mathrm{a}}$ & $1.6(0.6-2.5)$ & 0.009 & 0.037 & 0.591 \\
\hline CLDN4 & $1.1(0.3-1.6)$ & $1.1(0.2-2.3)$ & $1.3(0.4-1.5)$ & $1.5(1.0-1.8)$ & $1.6(1.2-1.9)$ & $1.4(0.7-1.8)$ & 0.075 & 0.713 & 0.413 \\
\hline OCLN & $0.7(0.5-1.7)$ & $0.7(0.5-1.2)$ & $1.0(0.5-2.4)$ & $1.0(0.6-2.4)$ & $1.3(0.8-3.6)$ & $1.0(0.5-1.5)$ & 0.446 & 0.649 & 0.113 \\
\hline $\mathrm{ZO}-1$ & $4.1(0.4-10.9)$ & $7.4(1.4-13.8)$ & $1.5(0.3-7.6)$ & $1.0(0.2-5.6)$ & $1.9(0.5-7.1)$ & $0.7(0.2-5.2)$ & 0.118 & 0.648 & 0.147 \\
\hline
\end{tabular}

${ }^{a}$ Statistically significant compared to male control group.

FD, functional dyspepsia; CLDN, claudin; OCLN, occludin; ZO-1, zonula occludens-1.

Data are presented as median (interquartile range).
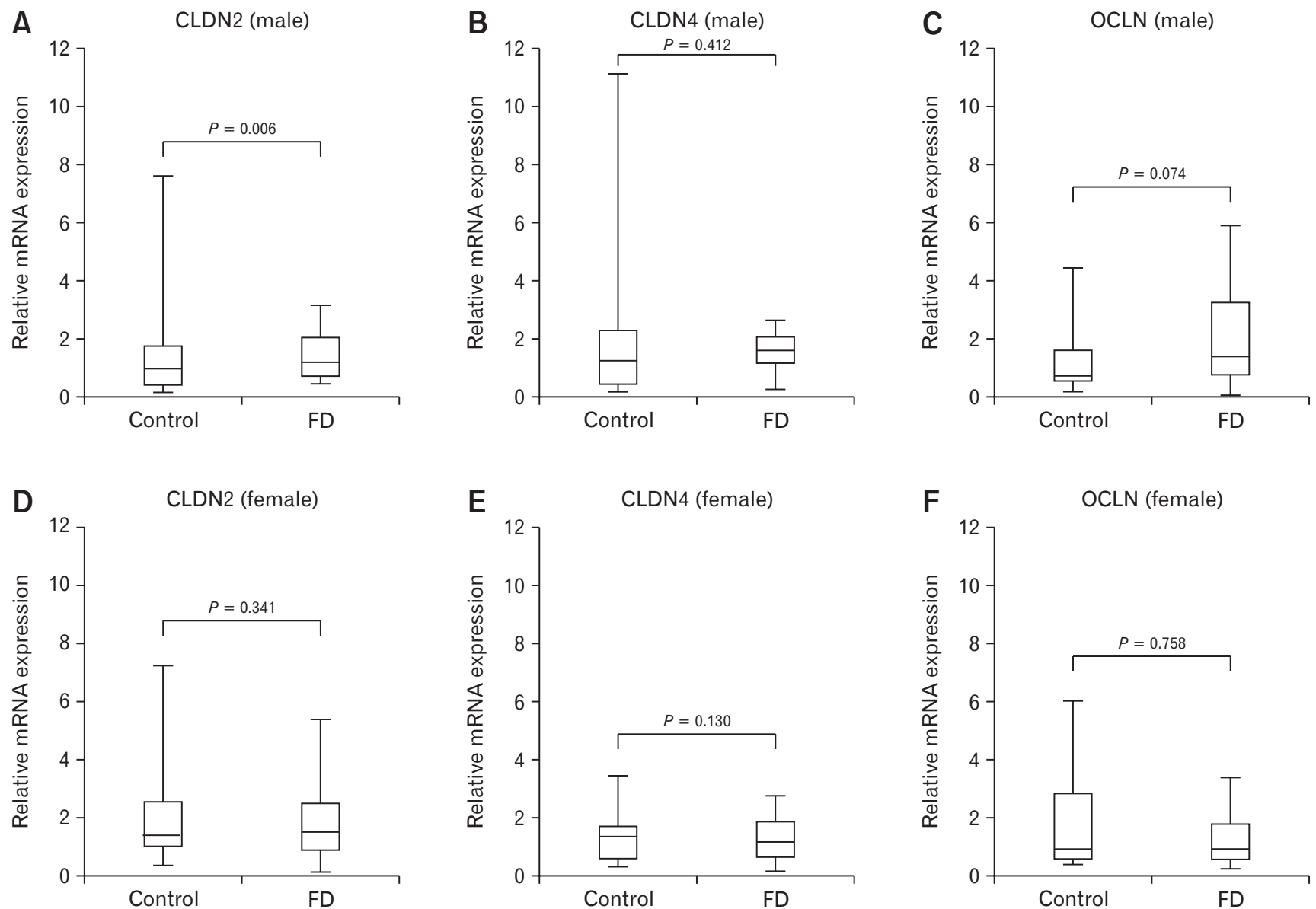

Figure 2. Comparison of tight junction protein mRNA expression levels in the control and functional dyspepsia (FD) groups in Helicobacter pylori-uninfected subjects. (A-C) Only claudin-2 (CLDN2) mRNA expression was significantly higher in male FD group than that of control group $(P=0.006)$. (D-F) There were no significant differences in CLDN2, CLDN4, and occludin (OCLN) mRNA expression level between female FD group and female control group. Data are expressed as median (interquartile range). 
0.018) (Table 2). CLDN2, CLDN4, and OCLN mRNA expression were higher in male FD group than those of control group $(P=$ $0.017,0.054$, and 0.044 , respectively), however, there were no significant differences in mRNA expression level of TJPs between female FD group and female control group (Fig. 1).

\section{Tight Junction Protein mRNA Expression Levels Between the Control and Functional Dyspepsia Groups in Helicobacter pylori Uninfected Subjects}

Among $88 \mathrm{H}$. pylori uninfected subjects, 30 and 58 subjects were assigned to the control and FD groups, respectively. The control group consisted of 15 males and 15 females and the FD group consisted of 23 males and 35 females. FD group showed significantly higher CLDN2 mRNA levels than those of control group $(P=0.009)$, however, there were no significant differences in CLDN1, CLDN4, OCLN, and ZO-1 mRNA expression levels between the control group and the FD group (Table 3). However, in sex specific analysis, the level of CLDN2 mRNA expression in male FD group was significantly higher than that of male control group $(P=0.006)$ (Fig. 2). In the control group, female group demonstrated significantly higher CLDN2 mRNA levels than that of the male group $(P=0.037)$. The level of CLDN1 mRNA expression in the male FD group was significantly higher than the female $\mathrm{FD}$ group $(P=0.014)$ (Table 3).

\section{Tight Junction Protein mRNA Expression Levels in Functional Dyspepsia Subtypes According to Sex in Helicobacter pylori Uninfected Subjects}

There were no significant differences in the mRNA expression levels of CLDN1, CLDN4, OCLN, and ZO-1 among FD subtypes (PDS, EPS, and Mixed). However, the level of CLDN2 mRNA expression was significantly higher in the male PDS group than in the male control group $(P=0.001)$, and the level of CLDN2 mRNA expression was significantly higher in the male EPS group than in the male control group $(P=0.023)$ (Fig. 3 and Table 4). The level of ZO-1 mRNA expression was significantly lower in female EPS group than those of male EPS group $(P=0.024)$ (Table 4).

\section{Expression of Zonula Occludens-1, Occludin, and Claudin-2 in Gastric Cell Lines After Helicobacter pylori Infection}

We next examined Western blot analysis whether $H$. pylori infection affects the expression of ZO-1, OCLN, and CLDN2 (Fig. 4A). HFE-145 cell lines were cultured with ATCC 43504 strain of $H$. pylori for 24 hours and 48 hours. We observed the ex- pression of ZO-1, OCLN, and CLDN2 in H. pylori uninfected gastric cell line. When comparing with control, the expression of ZO-1 and CLDN2 did not reach statistical significance at 12 hours and 48 hours (Fig. 4B and 4D), however, the expression of OCLN was significantly elevated 48 hours after the culture with ATCC 43504 (Fig. 4C).

\section{Discussion}

In this study, all groups irrespective of $H$. pylori status, FD group showed significantly higher CLDN2 mRNA levels than control group and the level of CLDN4 mRNA expression was significantly lower in female FD group than those of male FD group. However, in $H$. pylori uninfected subjects, the statistical difference of CLDN4 mRNA expression level between the male FD and female FD group disappeared, on the other hand, the level of CLDN1 mRNA expression in female FD group was significantly lower than that of male FD group.

TJPs consist of transmembrane proteins, including occludin, claudins, and junctional adhesion molecule, and peripheral scaffolding proteins, such as ZO-1. ${ }^{28,29}$ Claudin plays an important role in regulation of the permeability of $\mathrm{TJs} .{ }^{28}$ While most $\mathrm{TJPs}$ play a role in cell barriers maintainence, ${ }^{29}$ claudin is known to form a gated paracellular channel that allows sodium ions and other charged ions to pass between adjacent cells. ${ }^{30-32}$ Claudin-2 is typically expressed

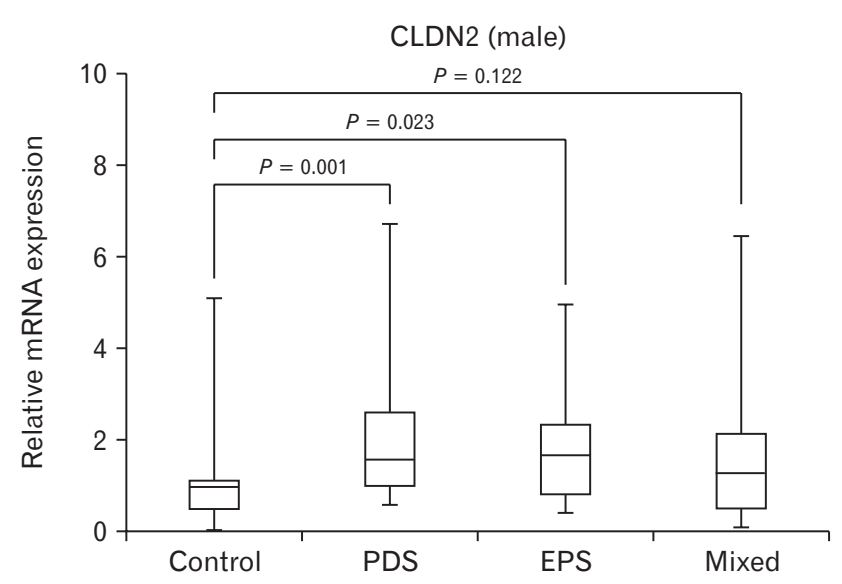

Figure 3. Comparison of claudin-2 (CLDN2) mRNA expression levels according to functional dyspepsia subtypes in male Helicobacter pylori uninfected subjects. The level of CLDN2 mRNA expression was significantly higher in postprandial distress syndrome (PDS) group than that of control group $(P=0.001)$ and the level of CLDN2 mRNA expression was significantly higher in epigastric pain syndrome (EPS) group than that of control group $(P=0.023)$. Data are expressed as median (interquartile range). 
Table 4. Comparison of Tight Junction Protein mRNA Expression Levels in Functional Dyspepsia Subtype According to Sex in Helicobacter pylori Uninfected Subjects

\begin{tabular}{|c|c|c|c|c|c|}
\hline Tight junction protein & $\begin{array}{l}\text { Control } \\
(\mathrm{n}=50)\end{array}$ & $\begin{array}{c}\text { PDS } \\
(n=26)\end{array}$ & $\begin{array}{c}\text { EPS } \\
(n=27)\end{array}$ & $\begin{array}{c}\text { Mixed } \\
(\mathrm{n}=45)\end{array}$ & $\begin{array}{c}P \text {-value } \\
\text { (FD subtypes) }\end{array}$ \\
\hline CLDN1 & $0.8(0.5-1.5)$ & $1.3(1.0-1.5)$ & $1.0(0.7-1.5)$ & $0.7(0.5-1.5)$ & 0.079 \\
\hline Male & $0.8(0.4-3.4)$ & $2.3(1.0-3.9)$ & $1.4(0.9-2.2)$ & $1.2(0.7-2.8)$ & 0.631 \\
\hline Female & $0.8(0.5-1.3)$ & $1.2(1.0-1.4)$ & $0.8(0.7-1.0)$ & $0.7(0.5-1.0)$ & 0.087 \\
\hline$P$-value (male vs female) & 0.513 & 0.259 & 0.284 & 0.076 & \\
\hline CLDN2 & $0.9(0.5-1.1)$ & $1.6(1.0-2.6)^{\mathrm{a}}$ & $1.6(0.8-2.3)^{\mathrm{a}}$ & $1.3(0.5-2.1)$ & 0.029 \\
\hline Male & $0.6(0.2-1.0)$ & $1.1(0.8-1.6)$ & $1.5(0.9-1.9)$ & $1.4(0.7-2.2)$ & 0.050 \\
\hline Female & $1.1(0.6-1.5)$ & $2.4(1.5-3.2)$ & $1.7(0.7-3.2)$ & $1.1(0.4-2.0)$ & 0.209 \\
\hline$P$-value (male vs female) & 0.037 & 0.106 & 0.622 & 0.621 & \\
\hline CLDN4 & $1.1(0.3-1.6)$ & $1.5(1.0-1.8)$ & $1.6(1.3-2.0)$ & $1.4(0.7-1.8)$ & 0.238 \\
\hline Male & $1.1(0.2-2.3)$ & $1.4(0.7-1.8)$ & $1.6(1.4-2.0)$ & $1.7(1.2-1.9)$ & 0.730 \\
\hline Female & $1.3(0.4-1.5)$ & $1.5(1.1-1.8)$ & $1.6(0.9-2.3)$ & $1.3(0.6-1.8)$ & 0.306 \\
\hline$P$-value (male vs female) & 0.713 & 0.805 & 1.000 & 0.302 & \\
\hline OCLN & $0.8(0.5-1.7)$ & $1.5(0.5-3.7)$ & $1.3(0.6-2.6)$ & $1.0(0.6-1.3)$ & 0.608 \\
\hline Male & $0.8(0.5-1.2)$ & $1.9(0.7-5.7)$ & $2.0(1.0-3.3)$ & $1.1(0.6-2.7)$ & 0.261 \\
\hline Female & $1.1(0.5-2.4)$ & $1.1(0.4-3.4)$ & $1.0(0.5-2.0)$ & $1.0(0.5-1.1)$ & 0.871 \\
\hline$P$-value (male vs female) & 0.649 & 0.639 & 0.214 & 0.443 & \\
\hline $\mathrm{ZO}-1$ & $4.1(0.4-10.9)$ & $0.5(0.1-10.6)$ & $0.6(0.1-1.2)$ & $1.7(0.5-6.0)$ & 0.092 \\
\hline Male & $7.4(1.4-13.8)$ & $4.9(0.4-14.3)$ & $1.4(1.1-6.1)$ & $1.9(0.5-5.0)$ & 0.691 \\
\hline Female & $1.5(0.3-7.6)$ & $0.2(0.1-2.0)$ & $0.4(0.1-0.8)$ & $1.2(0.7-5.4)$ & 0.063 \\
\hline$P$-value (male vs female) & 0.648 & 0.310 & 0.024 & 0.953 & \\
\hline
\end{tabular}

${ }^{a}$ Statistically significant compared to control group.

PDS, postprandial distress syndrome; EPS, epigastric pain syndrome; FD, functional dyspepsia; CLDN, claudin; OCLN, occludin; ZO-1, zonula occludens-1. Data are presented as median (interquartile range).

in leaky epithelia such as in the small intestine and provides a major pathway for the paracellular transport of sodium, potassium, and fluids. Thus, claudin-2 expression is linked with increased paracellular permeability. ${ }^{33}$ Diseases like Crohn's disease, ulcerative colitis, and celiac disease are characterized by impaired intestinal barrier function; ${ }^{34}$ when the barrier function is compromised, claudin-2 is upregulated, while occludin-3, $-4,-5,-8$, and occludin, which have sealing properties, are downregulated and redistributed out of the TJ domain. ${ }^{34-36}$ Taki et $\mathrm{al}^{15}$ found that duodenal mucosal CLDN3 mRNA expression was increased in FD patients. TJPs and their associated proteins are currently attracting attention, but the data interpretation remains difficult and confusing. Intracellular junctions exist on the most apical side of gastric and colonic columnar epithelial cells. TJs can be identified by fluorescence staining, so occludin or ZO-1 can be identified by special staining of intercellular contacts. However, claudin, which functions as a major TJ protein, is not only strongly identified by staining the apical side but also widely distributed throughout the lateral side of epithelial cells. Therefore, these data demonstrate that the claudin staining on the cell surface does not necessarily represent TJ strand formation. In other words, claudins are expressed on both apical side TJ complexes and at the lateral side of epithelial cells where TJs are absent, and the function of claudins expressed at the lateral side remains unclear. ${ }^{13}$ However, little is known about the expression of claudin protein in the stomach, and further research is needed.

The function of occludin is not yet fully understood regardless of the $H$. pylori status. Numerous studies indicate that occludin has crucial roles in the TJ structure and permeability. ${ }^{37}$ Recent studies showed that occludin knockdown induces an increase in paracellular permeability to macromolecules, which indicated that occludin plays a role in the maintenance and assembly of TJs. ${ }^{37}$ Occludin is highly phosphorylated on the serine and threonine residues, ${ }^{38}$ and the phosphorylation has a role in the maintenance and assembly of the TJ structures. ${ }^{39}$ Several studies have shown that tyrosine phosphorylation is caused during disassembly by various stimuli, ${ }^{40}$ and underlying this mechanism, the tyrosine phosphorylation of occludin attenuates the interaction with ZO-1 leading to dissociation from the junctional complex. ${ }^{41}$

In normal adult gastric mucosa, strong membranous positive staining for claudin-18 was observed. In contrast, in intestinalized 
A

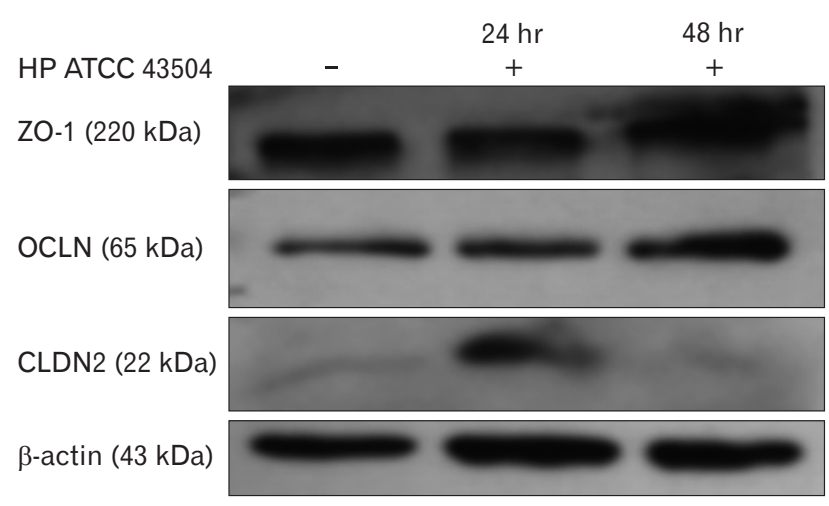

C

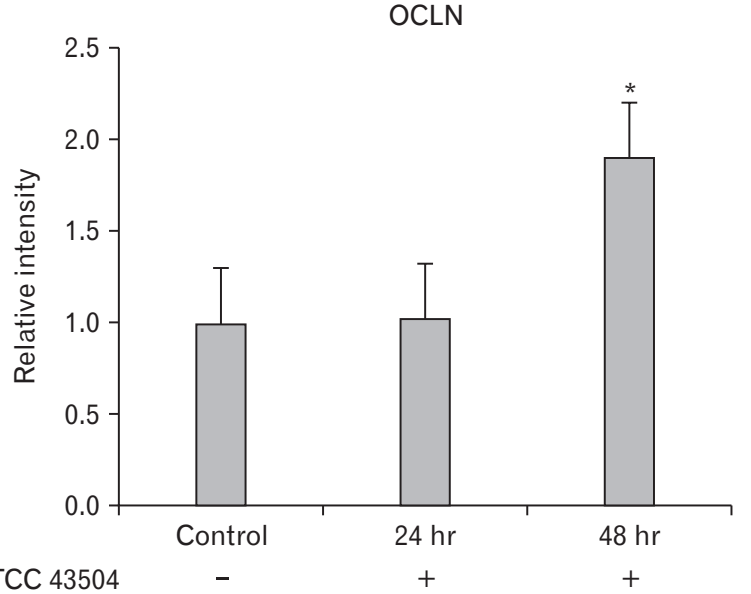

B

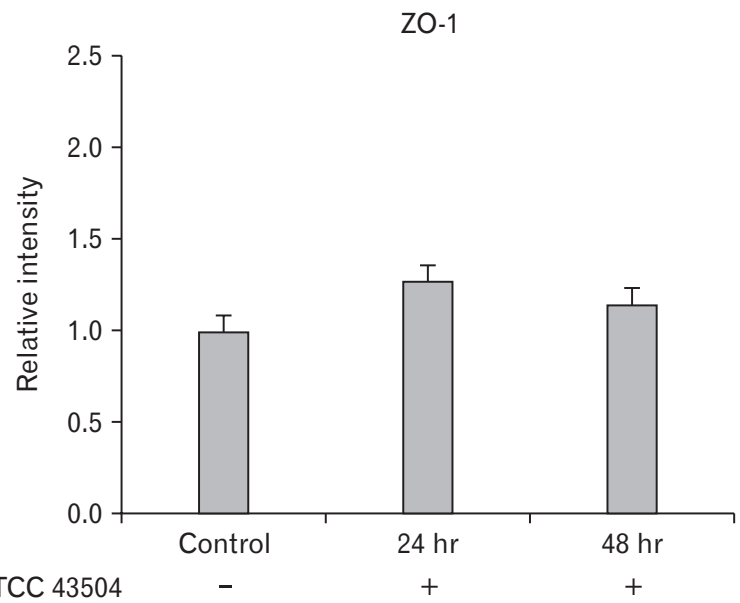

D

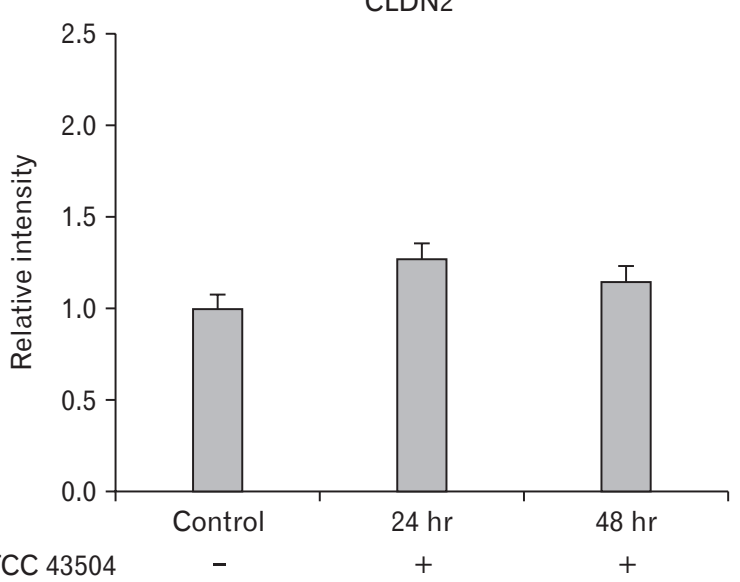

Figure 4. Expression of zonula occludens-1 (ZO-1), occludin (OCLN), and claudin-2 (CLDN2) in HFE 145 cell lines after cultured with Helicobacter pylori 43504 strain (HP ATCC 43504; O4 strain). (A) Western blot analysis of ZO-1, OCLN, and CLDN2. (B, D) There were no significant differences in the expression of ZO-1 and CLDN2 between control and H. pylori infection group. (C) The expression of OCLN was significantly elevated 48 hours after the culture with $H$. pylori strain 43504 . Data are expressed as means \pm SE for 3 experiments. ${ }^{*} P<0.05$ significantly different from the control.

glands showed positive membranous immunoreactivity for claudin-3, -4 and, $-7 .^{42}$ Thus, it can be said that atrophic mucosa and/ or intestinal metaplasia largely affect the pattern of TJPs especially claudin-3, -4, -7, and -18. H. pylori inhibits mucosal barrier function by using various virulence factors. Inflammation caused by $H$. pylori can cause the dysfunction of gastric TJPs. Experiments with gastric HGE-20 cells showed that IL-1 receptor phosphorylation by IL-1 $\beta$ develops after expose to $H$. pylori, lead to reduce claudin-4 expression. ${ }^{43}$ In experiments with NCI-N87 cells, exposure to H. pylori was found to reduce transepithelial resistance (TER) and increase paracellular permeability with concomitant increases in IL8, IL-6, IFN- $\gamma$, IL- $1 \beta$, TNF- $\alpha$, and IL- $10 .^{44}$ In addition, barrier dysfunction through the reorganization of ZO-1 and claudin-1 has also been demonstrated. ${ }^{44}$ However, the study of cell experiments is not yet fully established, and it is not yet known which cytokine influences barrier dysfunction. The most consistent results of TJ dysfunction caused by $H$. pylori virulence factors were from studies on urease and ammonia, ${ }^{28}$ that are seems to cause the cytoskeletal rearrangement of $\mathrm{TJ} .{ }^{45} H$. pylori can affect TER and permeability by neutralizing gastric acid by producing ammonia. ${ }^{44}$ In an experiment on HGE-20 cells, high ammonia/ammonium-producing isogenic ureB-negative $H$. pylori mutants influenced luminal acidity, producing a significant increase in TER and a significant decrease in paracellular permeability. ${ }^{46} \mathrm{~A}$ recent ex vivo study using human gastroid monolayers demonstrated declined transepithelial electrical resistance following $H$. pylori inoculation and minimal disruption 
of ZO-1 or E-cadherin structure were observed by confocal scanning microscopy. ${ }^{47}$

Similar to our previous study, ${ }^{10}$ female patients with FD were more anxious and had a more impaired QoL than male patients with FD. Emerging evidence provided by recent epidemiological studies indicates that anxiety or depression and functional GI symptoms were positively associated. ${ }^{48}$ Anxiety has been reported to show a negative correlation with pain threshold. ${ }^{49}$ Therefore, more attention is needed for psychological evaluations and management when caring for female FD patients. FD patients showed poorer QoL than the control group, especially on the physical and social domains, indicating the need for more active medical interventions.

The several limitations of this study are as follows. First, this study was a single center study, and the sample size was relatively small. Second, symptom scores were assessed only by questionnaire, which has the risk of recall bias. Third, the mRNA expression value of CLDN2 in the female control group was significantly higher than that of the male control group. It is difficult to conclude exactly because there are no studies comparing claudin-2 levels in normal males and females. However, there is a possibility of false positives caused by using only qRT-PCR. However, the protein expression of CLDN2 was increased in HFE-145 cell lines when cultured with $H$. pylori strain 43504 without the statistical significance. In contrast, expression of OCLN showed statistically significant increase suggesting that $H$. pylori infection differently affect the TJPs. Despite these limitations, in our study, we found sex-based differences in FD regarding the expression of various TJPs that reflect gastric mucosal permeability.

In conclusion, the results of our study indicate that $H$. pylori can affect a variety of TJPs, particularly claudin-4 and occludin. Increase in claudin-2 is thought to be involved in FD irrespective of $H$. pylori status, especially in the pathophysiology of male FD. Further studies are needed to clarify these findings.

\section{Supplementary Material}

Note: To access the supplementary table mentioned in this article, visit the online version of Journal of Neurogastroenterology and Motility at http://www.jnmjournal.org/, and at https://doi. org/10.5056/jnm19208.

Financial support: This research was supported by Support Program for Women in Science, Engineering and Technology through the Center for Women in Science, Engineering and Technology (WISET) funded by the Ministry of Science and ICT (No.
WISET202003GI01).

Conflicts of interest: None.

Author contributions: Ju Yup Lee analyzed data and drafted the article; Nayoung Kim designed this study, collected the data, and supervised the writing of this manuscript; Yoon Jin Choi helped to analyze data; Ji Hyun Park performed molecular studies; Hassan Ashktorab and Duane T Smoot provided HFE 145 cell line; and Dong Ho Lee supervised the writing of the manuscript. All authors have read and approved the final draft of this paper.

\section{References}

1. Talley NJ, Ford AC. Functional dyspepsia. N Engl J Med 2015;373:1853-1863.

2. Stanghellini V, Chan FK, Hasler WL, et al. Gastroduodenal disorders. Gastroenterology 2016;150:1380-1392.

3. Houghton LA, Heitkemper M, Crowell M, et al. Age, gender and women's health and the patient. Gastroenterology 2016;150:1332-1343. e4.

4. Chang L, Toner BB, Fukudo S, et al. Gender, age, society, culture, and the patient's perspective in the functional gastrointestinal disorders. Gastroenterology 2006;130:1435-1446.

5. Talley NJ, Zinsmeister AR, Schleck CD, Melton LJ 3rd. Dyspepsia and dyspepsia subgroups: a population-based study. Gastroenterology 1992;102(4 Pt 1):1259-1268.

6. Aro P, Talley NJ, Ronkainen J, et al. Anxiety is associated with uninvestigated and functional dyspepsia (Rome III criteria) in a Swedish population-based study. Gastroenterology 2009;137:94-100.

7. Zagari RM, Law GR, Fuccio L, et al. Epidemiology of functional dyspepsia and subgroups in the Italian general population: an endoscopic study. Gastroenterology 2010;138:1302-1311.

8. Oshima T, Miwa H. Epidemiology of functional gastrointestinal disorders in Japan and in the world. J Neurogastroenterol Motil 2015;21:320-329.

9. Stanghellini V, Tosetti C, Paternico A, et al. Risk indicators of delayed gastric emptying of solids in patients with functional dyspepsia. Gastroenterology 1996;110:1036-1042.

10. Choi YJ, Park YS, Kim N, et al. Gender differences in ghrelin, nociception genes, psychological factors and quality of life in functional dyspepsia. World J Gastroenterol 2017;23:8053-8061.

11. Vanheel H, Farré R. Changes in gastrointestinal tract function and structure in functional dyspepsia. Nat Rev Gastroenterol Hepatol 2013;10:142-149.

12. Vivinus-Nébot M, Frin-Mathy G, Bzioueche H, et al. Functional bowel symptoms in quiescent inflammatory bowel diseases: role of epithelial barrier disruption and low-grade inflammation. Gut 2014;63:744-752.

13. Oshima T, Miwa H. Gastrointestinal mucosal barrier function and diseases. J Gastroenterol 2016;51:768-778.

14. Tsukita S, Furuse M, Itoh M. Multifunctional strands in tight junctions. Nat Rev Mol Cell Biol 2001;2:285-293. 
15. Taki M, Oshima T, Li M, et al. Duodenal low-grade inflammation and expression of tight junction proteins in functional dyspepsia. Neurogastroenterol Motil 2019;31:e13576.

16. Lee JY, Kim N, Park JH, et al. Expression of neurotrophic factors, tight junction proteins, and cytokines according to irritable bowel syndrome subtype and sex. J Neurogastroenterol Motil 2020;26:106-116.

17. Choi YJ, Kim N, Kim J, Lee DH, Park JH, Jung HC. Upregulation of vanilloid receptor-1 in functional dyspepsia with or without Helicobacter pylori infection. Medicine (Baltimore) 2016;95:e3410.

18. Choi YJ, Kim N, Yoon H, et al. Increase in plasma acyl ghrelin levels is associated with abatement of dyspepsia following Helicobacter pylori eradication. J Gastroenterol 2016;51:548-559.

19. Vakil N, Halling K, Ohlsson L, Wernersson B. Symptom overlap between postprandial distress and epigastric pain syndromes of the Rome III dyspepsia classification. Am J Gastroenterol 2013;108:767-774.

20. Song KH, Jung HK, Min BH, et al. Development and validation of the Korean Rome III questionnaire for diagnosis of functional gastrointestinal disorders. J Neurogastroenterol Motil 2013;19:509-515.

21. Lewis SJ, Heaton KW. Stool form scale as a useful guide to intestinal transit time. Scand J Gastroenterol 1997;32:920-924.

22. Kim JY, Kim N, Seo PJ, et al. Association of sleep dysfunction and emotional status with gastroesophageal reflux disease in Korea. J Neurogastroenterol Motil 2013;19:344-354.

23. Bjelland I, Dahl AA, Haug TT, Neckelmann D. The validity of the hospital anxiety and depression scale. An updated literature review. J Psychosom Res 2002;52:69-77.

24. Skevington SM, Lotfy M, O'Connell KA. The world health organization's WHOQOL-BREF quality of life assessment: psychometric properties and results of the international field trial. A report from the WHOQOL group. Qual Life Res 2004;13:299-310.

25. Min SK, Kim KI, Lee CI, Jung YC, Suh SY, Kim DK. Development of the Korean versions of WHO quality of life scale and WHOQOLBREF. Qual Life Res 2002;11:593-600.

26. Oh SM, Min KJ, Park DB. A study on the standardization of the hospital anxiety and depression scale for Koreans: a comparison of normal, depressed and anxious groups. J Korean Neuropsychiatr Assoc 1999;38:289-296.

27. Dixon MF, Genta RM, Yardley JH, Correa P. Classification and grading of gastritis. The updated Sydney system. International workshop on the histopathology of gastritis, Houston 1994. Am J Surg Pathol 1996;20:1161-1181.

28. Caron TJ, Scott KE, Fox JG, Hagen SJ. Tight junction disruption: Helicobacter pylori and dysregulation of the gastric mucosal barrier. World $\mathrm{J}$ Gastroenterol 2015;21:11411-11427.

29. Günzel D, Yu AS. Claudins and the modulation of tight junction permeability. Physiol Rev 2013;93:525-569.

30. Weber CR, Liang GH, Wang Y, et al. Claudin-2-dependent paracellular channels are dynamically gated. Elife 2015;4:e09906.

31. Amasheh S, Meiri N, Gitter AH, et al. Claudin-2 expression induces cation-selective channels in tight junctions of epithelial cells. J Cell Sci 2002;115(Pt 24):4969-4976.

32. Muto S, Hata M, Taniguchi J, et al. Claudin-2-deficient mice are defective in the leaky and cation-selective paracellular permeability properties of renal proximal tubules. Proc Natl Acad Sci USA 2010;107:8011-8016.

33. Luettig J, Rosenthal R, Barmeyer C, Schulzke JD. Claudin-2 as a mediator of leaky gut barrier during intestinal inflammation. Tissue Barriers 2015;3:e977176.

34. Prasad S, Mingrino R, Kaukinen K, et al. Inflammatory processes have differential effects on claudins 2, 3 and 4 in colonic epithelial cells. Lab Invest 2005;85:1139-1162.

35. Zeissig S, Bürgel N, Günzel D, et al. Changes in expression and distribution of claudin 2, 5 and 8 lead to discontinuous tight junctions and barrier dysfunction in active Crohn's disease. Gut 2007;56:61-72.

36. Das P, Goswami P, Das TK, et al. Comparative tight junction protein expressions in colonic Crohn's disease, ulcerative colitis, and tuberculosis: a new perspective. Virchows Arch 2012;460:261-270.

37. Al-Sadi R, Khatib K, Guo S, Ye D, Youssef M, Ma T. Occludin regulates macromolecule flux across the intestinal epithelial tight junction barrier. Am J Physiol Gastrointest Liver Physiol 2011;300:G1054-G1064.

38. Sakakibara A, Furuse M, Saitou M, Ando-Akatsuka Y, Tsukita S. Possible involvement of phosphorylation of occludin in tight junction formation. J Cell Biol 1997;137:1393-1401.

39. Rao R. Occludin phosphorylation in regulation of epithelial tight junctions. Ann NY Acad Sci 2009;1165:62-68.

40. Elias BC, Suzuki T, Seth A, et al. Phosphorylation of Tyr-398 and Tyr402 in occludin prevents its interaction with ZO-1 and destabilizes its assembly at the tight junctions. J Biol Chem 2009;284:1559-1569.

41. Lee SH. Intestinal permeability regulation by tight junction: implication on inflammatory bowel diseases. Intest Res 2015;13:11-18.

42. Shinozaki A, Ushiku T, Morikawa T, et al. Epstein-Barr virus-associated gastric carcinoma: a distinct carcinoma of gastric phenotype by claudin expression profiling. J Histochem Cytochem 2009;57:775-785.

43. Lapointe TK, O'Connor PM, Jones NL, Menard D, Buret AG. Interleukin-1 receptor phosphorylation activates Rho kinase to disrupt human gastric tight junctional claudin-4 during Helicobacter pylori infection. Cell Microbiol 2010;12:692-703.

44. Fiorentino M, Ding H, Blanchard TG, Czinn SJ, Sztein MB, Fasano A. Helicobacter pylori-induced disruption of monolayer permeability and proinflammatory cytokine secretion in polarized human gastric epithelial cells. Infect Immun 2013;81:876-883.

45. Abu-Farsakh S, Wu T, Lalonde A, Sun J, Zhou Z. High expression of Claudin-2 in esophageal carcinoma and precancerous lesions is significantly associated with the bile salt receptors VDR and TGR5. BMC Gastroenterol 2017;17:33.

46. Marcus EA, Vagin O, Tokhtaeva E, Sachs G, Scott DR. Helicobacter pylori impedes acid-induced tightening of gastric epithelial junctions. Am J Physiol Gastrointest Liver Physiol 2013;305:G731-G739.

47. Uotani T, Murakami K, Uchida T, et al. Changes of tight junction and interleukin-8 expression using a human gastroid monolayer model of Helicobacter pylori infection. Helicobacter 2019;24:e12583.

48. Wu JC. Psychological co-morbidity in functional gastrointestinal disorders: epidemiology, mechanisms and management. J Neurogastroenterol Motil 2012;18:13-18.

49. Van Oudenhove L, Vandenberghe J, Geeraerts B, et al. Relationship between anxiety and gastric sensorimotor function in functional dyspepsia. Psychosom Med 2007;69:455-463. 